\title{
Relationship between the GOLD combined COPD assessment staging system and bacterial isolation
}

This article was published in the following Dove Press journal:

International Journal of COPD

27 September 2014

Number of times this article has been viewed

\section{Yusuf Aydemir' \\ Özlem Aydemir ${ }^{2}$ \\ Fatma Kalem ${ }^{3}$}

'Department of Respiratory Medicine, Sakarya University, Sakarya, Turkey;

${ }^{2}$ Department of Microbiology, Sakarya University, Sakarya, Turkey;

${ }^{3}$ Department of Microbiology, Konya

Numune Hospital, Konya, Turkey
Correspondence: Yusuf Aydemir Department of Respiratory Medicine, Sakarya University Hospital,

54100 Sakarya, Turkey

Tel +902642956630

Fax +902642956629

Email dryaydemir@yahoo.com
Background: Acute exacerbations, which are a significant cause of mortality and morbidity, adversely affect chronic obstructive pulmonary disease (COPD) prognosis by accelerating loss of lung function. It is important to know the microorganisms that commonly cause exacerbations in the patient groups classified according to clinical and functional characteristics for fast and accurate treatment of acute exacerbations.

Objectives: The last Global Initiative for Chronic Obstructive Lung Disease (GOLD) publication recommended a new staging system containing obstruction degree, frequency of exacerbations, and quality of life questionnaires. This study is designed to analyze the relationship between the bacteria isolated in acute exacerbations and new GOLD stages.

Methods: Potentially pathogenic bacteria (PPB) isolation with culture and polymerase chain reaction methods were obtained from 114 acute exacerbation COPD patients, classified into A, B, C, and $\mathrm{D}$ groups by analyzing the forced expiratory volume in 1 second $\left(\mathrm{FEV}_{1}\right)$ value, COPD Assessment Test (CAT) score, and exacerbation frequency according to the new GOLD staging system.

Results: There was a significant correlation between exacerbation frequency and $\mathrm{PPB}$ isolation $(P=0.002)$. There was no relationship between GOLD stage, $\mathrm{FEV}_{1}$, and CAT score with PPB isolation. The isolated bacteria diversity and mixed infection frequency were higher in the GOLD stage D group. Pseudomonas aeruginosa, Escherichia coli, and Acinetobacter baumannii were isolated only from $\mathrm{D}$ group patients.

Conclusion: Bacterial infection may cause an acute exacerbation equally in each stage for COPD. The difference in bacterial etiology is more related to exacerbation frequency than FEV and CAT scores for an acute exacerbation. Determining exacerbation frequency is significant for treatment success in empirical antibiotic selection.

Keywords: chronic obstructive pulmonary disease, acute exacerbation, bacterial etiology, polymerase chain reaction, GOLD

\section{Introduction}

Some patients with chronic obstructive pulmonary disease (COPD) are prone to frequent exacerbations, which are a major cause of morbidity and mortality. The reduction and effective treatment of exacerbations may have significant benefits. ${ }^{1,2}$ Previous studies have shown that patients with severe or very severe air flow limitation tend to be at high risk of exacerbations. Higher exacerbation rates are associated with a faster loss of forced expiratory volume in 1 second $\left(\mathrm{FEV}_{1}\right)$ and greater worsening of overall health status. ${ }^{3-5}$

Most exacerbations of COPD are caused by bacterial infection. Studies with conventional methods have now established that approximately 50\% of exacerbations are caused by bacterial infection. Nevertheless, conventional diagnostic methods are often insufficient for etiological diagnosis, and in half of these cases the pathogen 
cannot be determined. ${ }^{6}$ The use of multiplex polymerase chain reaction (PCR), which is a reliable molecular method for diagnosing lower respiratory tract infections, has increased in recent years. The prominent advantage of the PCR method compared with culture is that since PCR is a method that is based on replicating the deoxyribonucleic acid (DNA) or ribonucleic acid (RNA) of a very small amount of microorganisms, it does not require living organisms and therefore is not affected by the use of antibiotics. In addition, PCR is more sensitive for the detection of multiple microorganisms and delivers fast results. ${ }^{6}$

Streptococcus pneumoniae, Haemophilus influenzae, and Moraxella catarrhalis are the most common bacterial pathogens involved in an exacerbation. ${ }^{1,6}$ This poses several questions, such as is it possible that the increased frequency of exacerbations in patients with more severe air flow limitations is related to the increase in infectious origin exacerbations? Or may the isolation of the bacterial agent be related to other clinical characteristics besides $\mathrm{FEV}_{1}$ ?

Previously, the Global Initiative for Chronic Obstructive Lung Disease (GOLD) publication defined and graded (stages 1, 2, 3, and 4) expiratory air flow obstruction. Because $\mathrm{FEV}_{1}$ does not reliably predict the degree of breathlessness, exercise limitation, exacerbations, and health status impairment in patients with COPD, the GOLD 2011 report added symptoms, including the COPD Assessment Test (CAT) and the Modified British Medical Research Council (mMRC), and exacerbation risk to help define risk groups and a severity staging system. ${ }^{1,7}$

In studies based on the previous GOLD staging system, a significant relationship between low $\mathrm{FEV}_{1}$ and frequency of various organisms, including Pseudomonas aeruginosa and Enterobacteriaceae, was shown. ${ }^{8-10}$ However, there have not been similar studies that have included symptom scores and exacerbation frequency in the groups classified according to the new GOLD staging system.

This study is designed to analyze the relationship of isolation frequency and the variety of potentially pathogenic bacteria (PPB) with new GOLD stages in acute exacerbations of COPD (AECOPD). PPB were obtained by conventional sputum culture and the PCR method. In addition, our study is one of the few studies comparing the highly sensitive PCR method with the culture method in AECOPD.

\section{Materials and methods Study design and population}

Consecutive patients with AECOPD who applied to the Konya Numune Hospital Pulmonology Department, Konya, Turkey, from September 2012 to December 2013 and who were ambulatory or undergoing inpatient treatment were included in this study. The patients were diagnosed with COPD according to GOLD 2011 criteria. The existence of three criteria described previously, dyspnea, sputum volume, and increase in sputum purulence, was searched in the diagnosis of acute exacerbation. ${ }^{11}$ Patients with a history of antibiotic use in the last 10 days, accompanying bronchiectasis (verified with high-resolution computed tomography), pneumonia, immunosuppression, malignancy, and congestive heart failure were not included in the study. CAT and a pulmonary function test, which is in accordance with the American Thoracic Society, were provided to the patients. All pulmonary function tests were performed by the same technician after the administration of $400 \mu \mathrm{g}$ salbutamol while the patient was stable. The exacerbation history was noted. The combined COPD assessment scaling was applied according to GOLD 2011 criteria. Patients were divided into four groups, GOLD A, B, C, and D. Sputum samples were taken from patients to a sterile container after rinsing the mouth and throat and were analyzed microscopically by Gram staining without waiting. Sputum samples that were observed to have fewer than ten epithelial cells and more than 25 leukocytes in each area upon $100 \times$ magnification were included in the study as appropriate sputum samples. All patients were informed about the study. Their written consents were taken. The consent of the Selçuk University Meram Medical Faculty Ethics Committee was taken for the study.

\section{Microbiological sputum analysis}

After Gram staining and direct microscopic examination, sputum samples were incubated for $18-36$ hours at $37^{\circ} \mathrm{C}$ by inoculating in eosin methylene blue agar, blood agar, Brucella agar, and chocolate agar media. The results were analyzed.

\section{Multiplex PCR/reverse line blot hybridization analysis}

The clinical samples, such as genomic DNA isolation, PCR step, and reverse line blot hybridization on the assay, were studied by the multiplex PCR method with a CAP-Bac-PN Mix (Gen ID ${ }^{\circledR}$; Autoimmun Diagnostika GmbH, Straßberg, Germany) kit. In the study, detection of $S$. pneumoniae, H. influenzae, M. catarrhalis, Chlamydophila pneumoniae, Mycoplasma pneumoniae, Legionella pneumophila, Staphylococcus aureus, Klebsiella pneumoniae, Escherichia coli, and Enterobacter cloacae bacteria was done with an RDB 2245/RDB 2246 BAC HOSPITAL (Gen ID ${ }^{\circledR}$; Autoimmun 
Diagnostika $\mathrm{GmbH}$ ) multiplex PCR kit according to the experts' suggestions.

\section{Statistical analysis}

The SPSS version 21 (IBM Corporation, Armonk, NY, USA) program was used for statistical analysis. The independentsamples $t$-test for comparison of parametric data among groups, the Mann-Whitney $U$ test for comparison of nonparametric data, and the $\chi^{2}$ test for multiple nonparametric group comparisons were used. The limit for statistical significance was accepted as $P<0.05$.

\section{Results}

A total of 114 patients, whose ages ranged from 39 years to 86 years and who consisted of 86 males and 28 females, were included in the study. Among the four groups that were divided according to GOLD stage, there was no difference in terms of age, sex, and smoking. General characteristics of the cases are presented in Table 1.
In the microscopic analysis of Gram-stained sputum samples, single or multiple bacteria were observed for $66.6 \%$ of the patients. The most frequent bacteria seen were Grampositive cocci with $33.3 \%$. There was a significant difference between stages in terms of bacteria observation rate with Gram staining $(P=0.036)$. Bacterial observation in group $\mathrm{D}$ occurred at a greater frequency.

\section{Culture results}

At least one bacterial growth was detected in 42 (36.8\%) patients' culture. The most commonly grown bacteria based on the culture studies were $S$. pneumoniae (10.5\%) and $H$. influenzae (8.8\%) (Table 2). Bacteria reproducing in group D were elevated in terms of quantity and diversity. P. aeruginosa, E. coli, and Acinetobacter baumannii were reproduced only in group D patients (Table 2). However, there was no significant difference between GOLD stage and culture results of the patients $(P=0.325)$. There was no

Table I General characteristics of the study population

\begin{tabular}{|c|c|c|c|}
\hline & $\mathbf{n}$ & & $\%$ \\
\hline Total patients & 140 & & \\
\hline Excluded patients & 26 & & \\
\hline \multirow[t]{4}{*}{ Due to } & 8 & Previous antibiotic treatment & \\
\hline & 8 & Poor cooperation PFT & \\
\hline & 6 & Accompanying comorbidities & \\
\hline & 4 & Not adequate quality of sputum & \\
\hline \multirow[t]{3}{*}{ Included patients } & 114 & & \\
\hline & 74 & Outpatients & \\
\hline & 40 & Inpatients & \\
\hline \multicolumn{4}{|l|}{ Sex } \\
\hline Male & 86 & & 75.4 \\
\hline Female & 28 & & 24.6 \\
\hline \multicolumn{4}{|l|}{ GOLD class } \\
\hline A & 14 & All of outpatients & 12.3 \\
\hline B & 30 & I inpatient & 26.3 \\
\hline C & 29 & 9 inpatients & 25.4 \\
\hline D & 41 & 30 inpatients & 36.0 \\
\hline \multicolumn{4}{|l|}{ Exacerbations } \\
\hline 0 & 27 & & 23.7 \\
\hline I & 37 & & 32.4 \\
\hline$\geq 2$ & 50 & & 43.9 \\
\hline Smoking & 36 & & 31.6 \\
\hline Pneumococcal vaccination & 26 & & 22.8 \\
\hline Age, mean (SD) & $65( \pm 9)$ & Minimum 39 & Maximum 86 \\
\hline $\mathrm{FEV}_{1} \%$, mean (SD) & $56( \pm 15)$ & Minimum 24 & Maximum 82 \\
\hline CAT, mean (SD) & $18( \pm 10)$ & Minimum 3 & Maximum 40 \\
\hline CRP, mg/mL, mean (SD) & $38.6(45)$ & Minimum 3 & Maximum 150 \\
\hline Leukocytes, $\times 10^{9}$ cells/L, mean (SD) & II.6 (4) & Minimum 6.I & Maximum 22.1 \\
\hline Sedimentation, mm/hour, mean (SD) & $26(15)$ & Minimum I & Maximum 7I \\
\hline
\end{tabular}

Abbreviations: CAT, COPD Assessment Test; COPD, Chronic Obstructive Lung Disease; CRP, C-reactive protein; FEV ${ }_{1}$, forced expiratory volume in I second; GOLD, Global Initiative for Chronic Obstructive Lung Disease; PFT, pulmonary function test; SD, standard deviation. 
Table 2 Distribution of culture and polymerase chain reaction (PCR) results according to Global Initiative for Chronic Obstructive Lung Disease stages

\begin{tabular}{|c|c|c|c|c|c|}
\hline & Total (\%) & $\mathbf{A}$ & B & C & D \\
\hline \multicolumn{6}{|l|}{ Culture } \\
\hline Normal flora & $72(63.1)$ & 10 & 19 & 20 & 23 \\
\hline Streptococcus pneumoniae & $12(10.5)$ & 1 & 5 & 2 & 4 \\
\hline Haemophilus influenzae & $10(8.8)$ & 2 & 3 & 3 & 2 \\
\hline Moraxella catarrhalis & $5(4.4)$ & I & 2 & 2 & \\
\hline Klebsiella pneumoniae & $5(4.4)$ & & I & I & 3 \\
\hline Pseudomonas aeruginosa & $5(4.4)$ & & & & 5 \\
\hline Escherichia coli & $2(1.7)$ & & & & 2 \\
\hline Staphylococcus aureus & $2(1.7)$ & & & I & I \\
\hline Acinetobacter baumannii & I (0.9) & & & & 1 \\
\hline Bacterial isolation total (\%) & 36.8 & 28.5 & 36.6 & 31 & 43.9 \\
\hline \multicolumn{6}{|l|}{$\mathbf{P C R}^{\mathbf{a}}$} \\
\hline Negative & $40(35.1)$ & 6 & 11 & 11 & 12 \\
\hline S. pneumoniae & $18(15.8)$ & 4 & 4 & 5 & 5 \\
\hline H. influenzae & $18(15.8)$ & 3 & 4 & 5 & 6 \\
\hline S. pneumoniae $+H$. influenzae & $8(7)$ & & 2 & 2 & 4 \\
\hline M. catarrhalis & $7(6.1)$ & 1 & 3 & I & 2 \\
\hline K. pneumoniae & $7(6.1)$ & & I & I & 5 \\
\hline S. pneumoniae + M. catarrhalis & $6(5.3)$ & & 2 & I & 3 \\
\hline E. coli & $3(2.6)$ & & & I & 2 \\
\hline H. influenzae + M. catarrhalis & $3(2.6)$ & & 2 & I & \\
\hline M. pneumoniae & $2(1.8)$ & & I & & I \\
\hline S. aureus $+H$. influenzae & $2(1.8)$ & & & I & 1 \\
\hline Bacterial isolation total (\%) & 64.9 & 57.1 & 63.3 & 62 & 70.7 \\
\hline
\end{tabular}

Note: ${ }^{\text {aThe }}$ PCR kit has no ability to detect $P$. aeruginosa and $A$. baumanii.

difference between age, $\mathrm{FEV}_{1}$, CAT scores, and exacerbation frequency with isolation in culture (Table 3 ).

\section{PCR results}

In the real-time PCR study, similar to the ratio of direct microscopy, at least one bacterial agent was obtained for $65 \%$ of the patients (Table 2).

In PCR, there was a significant difference between PPB isolation and exacerbation frequency $(P=0.002)$. There was no significant relationship between GOLD stages, $\mathrm{FEV}_{1}$, CAT scores, and age with PCR results (Tables 3 and 4). As in culture, quantity and diversity of bacteria in group D were higher. Moreover, mixed infectious agent frequency was observed to be elevated in group D. The distribution of bacteria according to stage is shown in Table 2 .

\section{PCR and culture comparison results}

When we compared the PCR and culture methods in terms of bacterial detection rate, the detection rate by PCR was significantly higher $(P=0.01)$. While bacterial growth was detected in cultures from 42 patients, the PCR method was able to detect bacteria in 74 patients. The PCR method detected bacteria in 40 out of 42 patients with positive cultures. There were only two patients who had positive cultures but did not have bacteria according to the PCR results. There was a significant difference between the culture and PCR methods in terms of detection rates of multiple pathogens $(P<0.001)$. The PCR method was able to detect multiple bacteria in 19 cases, while the culture method did not detect multiple pathogens in any of the tested cases.

\section{Discussion}

Our study was designed to investigate the relationship between PPB isolation frequency and GOLD stages in AECOPD. However, no relationship between stage and bacteria isolation was found. Similarly, there was no correlation between $\mathrm{FEV}_{1}$ and CAT scores with PPB frequency. We have found a significant relationship between PPB isolation and exacerbation frequency only.

Acute exacerbations adversely affect the prognosis of disease and accelerate the process, resulting in severe respiratory failure. They result in a considerable load on health care expenditure of countries and a significant amount of labor

Table 3 Relationship between various parameters and bacterial isolation

\begin{tabular}{|c|c|c|c|c|c|c|}
\hline & \multicolumn{3}{|l|}{ Culture } & \multicolumn{3}{|l|}{ PCR } \\
\hline & $\begin{array}{l}\text { Bacterial } \\
\text { isolation }\end{array}$ & $\begin{array}{l}\text { No bacterial } \\
\text { isolation }\end{array}$ & $P$-value & $\begin{array}{l}\text { Bacterial } \\
\text { isolation }\end{array}$ & $\begin{array}{l}\text { No bacterial } \\
\text { isolation }\end{array}$ & $P$-value \\
\hline Age (mean, years) & 66 & 65 & 0.483 & 65.7 & 64.4 & 0.574 \\
\hline Sex (n, female/male) & $10 / 31$ & $18 / 55$ & 0.381 & $19 / 58$ & $9 / 28$ & 0.599 \\
\hline CRP (mean, mg/mL) & 47.6 & 46 & 0.902 & 41.2 & 34.8 & 0.750 \\
\hline Leukocytes (mean, $\times 10^{9}$ cells/L) & 13.0 & 10.5 & 0.204 & 11.6 & 11.5 & 0.942 \\
\hline Sedimentation (mean, $\mathrm{mm} / \mathrm{hour}$ ) & 32.2 & 21.8 & 0.114 & 28.4 & 23.1 & 0.435 \\
\hline $\mathrm{FEV}_{1}$ (mean, \% predicted) & 57.8 & 53.6 & 0.251 & 54.7 & 59.5 & 0.184 \\
\hline CAT (mean) & 19.8 & 16.5 & 0.159 & 18.5 & 16.0 & 0.301 \\
\hline Exacerbations (mean) & 1.5 & 1.0 & 0.083 & $\mathrm{I} .43$ & 0.84 & 0.002 \\
\hline GOLD class ( $n$, groups $A / B / C / D)$ & $4 / 11 / 9 / 18$ & $10 / 19 / 20 / 23$ & 0.325 & $8 / 19 / 18 / 29$ & $6 / 11 / 11 / 12$ & 0.801 \\
\hline
\end{tabular}

Abbreviations: CAT, COPD Assessment Test; COPD, Chronic Obstructive Lung Disease; CRP, C-reactive protein; FEV , forced expiratory volume in I second; GOLD, Global Initiative for Chronic Obstructive Lung Disease; PCR, polymerase chain reaction. 
Table 4 Relationship between FEV , CAT, and exacerbation frequency with positive bacterial isolation

Positive bacterial isolation (PCR)

$\mathrm{FEV}_{1}>50 \%$ vs $\mathrm{FEV}_{1} \leq 50 \%$

P-value

CAT $<10$ vs CAT $\geq 10$

0.817

Exacerbations 0-I vs $\geq 2$

0.257

0.028

Abbreviations: CAT, COPD Assessment Test; COPD, COPD, Chronic Obstructive Lung Disease; PCR, polymerase chain reaction; $\mathrm{FEV}_{1}$, forced expiratory volume in I second.

force loss. However, there is controversy over which antibiotic treatment is needed for which exacerbations. The amount of sputum and evaluation of increase in its purulence seem to be the best method of indication to start antibiotic treatment. ${ }^{12}$ The determination of factors by conventional sputum culture methods is both difficult and time consuming. For this reason, clinicians initiated an empirical antibiotic treatment without waiting for the culture results. ${ }^{13}$ Knowing the frequency and resistance characteristics of microbiological organisms in exacerbation in that society is necessary for rational antibiotic selection and treatment success in the initiation of empirical antibiotic treatment. Many national and regional studies on agents with culture and serological methods have been conducted, and these studies have formed the foundation of empirical treatment, but there are a few studies with PCR.

In our study, similar to previous studies, S. pneumoniae and $H$. influenzae were the common bacteria in sputum culture, while $P$. aeruginosa, E. coli, and A. baumannii were isolated only in GOLD stage D patients. However, there was no significant difference between GOLD stage and culture results of the patients. In many studies of COPD acute exacerbations, S. pneumoniae, H. influenzae, and M. catarrhalis have been found to be predominant bacterial organisms. The degree of functional respiratory impairment in COPD patients has also been associated with the presence of different bacteria in their sputum samples during the course of an exacerbation. ${ }^{3,14}$ It has been shown that isolation ratios of $P$. aeruginosa, Enterobacteriaceae, and Gram-negative bacteria coincide with common factors in patients with severe and very severe COPD. ${ }^{8}$ In the study of Li et al, ${ }^{15}$ S. aureus, P. aeruginosa, E. coli, and A. baumannii were only isolated in patients with a $50 \% \mathrm{FEV}_{1}$ value. However, $S$. pneumoniae was found to occur more frequently in mild and moderate COPD, and $H$. influenzae was found approximately equally in three groups. In the study of Eller et al, ${ }^{8}$ a correlation between impaired lung function and bacteria isolation was obtained, and the frequency of Gram-negative organisms, including Pseudomonas, Klebsiella, and Enterobacteriaceae, was higher in severe and very severe patients. ${ }^{16}$
It is well known that conventional culture tests have low sensitivity and specificity for detecting microorganisms. The selective environment of the culture prevents the growth and presence of more than one type of organism. The other disadvantages are a consequence of using different media for different organisms and needing at least 2 days for results. Molecular techniques developed recently maintain very fast and reliable identification of respiratory infections. ${ }^{18,19}$ DNA or RNA from a very small amount of microorganisms can be isolated by PCR methods. In contrast to culture, PCR is not dependent on viable bacteria and is a valuable tool for the patients who need antibiotics. Strålin et a ${ }^{20}$ found that the $S$. pneumoniae isolation rate increased from $14 \%$ to $28 \%$, the H. influenzae isolation rate increased from $21 \%$ to $47 \%$, and the binary detection rate of microorganisms increased from $3 \%$ to $18 \%$ in the study comparing bronchoalveolar lavage fluids, culture, and PCR.

In the present study, PCR was more discriminatory than culture (positive samples 42 vs $74, P=0.01$ ). In 40 of 42 patients with positive cultures, the same microorganisms were detected by PCR. In only two samples was PCR negative. This situation can be explained by the presence of factors that may inhibit PCR in the samples (ie, blood, tissue, milk, or plant). Moreover, mixed infections, which cannot be found in culture, were detected by PCR $(n=19)$. Mixed infection frequency was higher in GOLD stage D patients $(n=8)$, but there was no significant difference between GOLD stage, $\mathrm{FEV}_{1}$, CAT scores, and PCR results. This study reveals only the relation between exacerbation frequency and bacterial isolation. Patients presenting frequent exacerbations have greater bacterial isolation, suggesting a greater degree of colonization. In fact, for many years, the existence of bacterial colonization of the airways has been known in patients with stable COPD. ${ }^{21}$ In comparative studies with healthy control groups, colonization of H. influenzae, S. pneumoniae, M. catarrhalis, P. aeruginosa, and $S$. aureus in the sputum ${ }^{5}$ and protected specimen brush ${ }^{22,23}$ samples of patients with stable COPD was present. Although the impact of colonized bacteria on an acute exacerbation has not yet been clear, it has been recently presented that an increase in bacterial load during exacerbations and proliferation of new strains has a relationship with acute exacerbations. ${ }^{24,25}$ When studies evaluating parameters associated with bacterial colonization are considered, Patel et al ${ }^{26}$ observed 29 patients with COPD for 529 days and found a significant relationship between exacerbation frequency and increased colonization but did not find any relationship between airway obstruction and colonization. Similarly, Zhang et al, ${ }^{5}$ in a study based on the observations 
of 46 patients with COPD for 1 year, presented a positive correlation between lower airway bacterial colonization and exacerbation frequency but could not find any relationship between $\mathrm{FEV}_{1}$ and colonization. Therefore, lower airway bacterial colonization seems to be more frequent for patients with frequent exacerbations. However, whether colonization causes frequent exacerbations or vice versa is not clear. ${ }^{3,14}$ In our study, PPB were isolated more frequently from patients with frequent exacerbations. Our study has not been designed for discriminating colonization or active infection. Because exacerbations were confirmed in all patients clinically, isolated PPB were considered as the cause of infection. Even if the isolated PPB reflects colonization, it can still be used as a indicator of infectious agents. This is because previous patients presenting colonization developed infections as a result of a new strain. In fact, in the Sethi et $\mathrm{al}^{27}$ study, over a period of 56 months, sputum samples for culture were collected monthly and during exacerbations from 81 outpatients with COPD. The PPB that was isolated during the stable period versus the exacerbation period illustrates the cause of the acute exacerbations as new strains of the pathogen.

In the present study, a relationship between exacerbation frequency and bacteria isolation was found. Hence, in terms of bacterial etiology, exacerbation frequency seems to be a better indicator compared with GOLD stage and $\mathrm{FEV}_{1}$.

Viral factors are responsible for approximately 15\%-30\% of exacerbations. ${ }^{9}$ Most commonly rhinoviruses, followed by metapneumovirus, influenza A and B, parainfluenza, coronavirus, adenovirus, and respiratory syncytial virus were isolated from patients with exacerbations. ${ }^{28}$ Also, from a significant proportion of patients, both bacterial and viral agents can be isolated. Mixed infections are more frequent in patients with severe COPD. Unfortunately, because of cost, our study did not identify concurrent viral pathogens, and this situation is one of the limitations of our study. Another limitation of our study is the small number of samples, due to high cost.

This study shows that bacterial infection in COPD may be an independent cause for acute exacerbations in each stage. There may be two reasons explaining why there was no difference in group D (which had frequent exacerbations, more symptoms, and lower $\mathrm{FEV}_{1}$ values) in terms of bacterial isolation frequency compared with other groups for patients classified according to the new GOLD staging. First, very severe patients with lung functions already at the lower limits are probably more sensitive to noninfectious agents such as air pollution and heart failure, and they show acute exacerbation symptoms more quickly. Air pollution and other environmental conditions that increase airway inflammation or bronchomotor tone may account for $15 \%-20 \%$ of exacerbations. ${ }^{6}$ The very high air pollution rate in the region where the study was conducted also supports this thesis. In this way, the conditions may be synchronized with a mild period for COPD patients who are not affected easily by noninfectious causes. Second, the average $\mathrm{FEV}_{1}$ in our study was very high ( $56 \%$ predicted). The average $\mathrm{FEV}_{1}$ for $\mathrm{D}$ group patients was $42.3 \%$. There may be differences in results for the severe COPD patients with lower FEV 1 values.

\section{Conclusion}

To our knowledge, the present study is the first to compare the new GOLD staging system and PPB isolation rate. In conclusion, isolated PPB variety and mixed infection frequency were found to be higher in GOLD group D patients. This result indicates the necessity for being cautious about the selection of empirical antibiotics for these patients. We propose the necessity of prospective studies that are based on long-term monitoring, contain groups with lower $\mathrm{FEV}_{1}$ scores, and are conducted with wide patient populations.

\section{Disclosure}

The authors report no conflicts of interest in this work.

\section{References}

1. National Heart, Lung, and Blood Institute. World Health Organization. Global Strategy for the Diagnosis, Management, and Prevention of Chronic Obstructive Pulmonary Disease. NHLBI/WHO Workshop Report 2011. Vestbo J. National Institutes of Health; 2014. Available from: http://www.goldcopd.org/guidelines-global-strategyfor-diagnosis-management.html. Accessed August 15, 2014.

2. Seemungal TA, Donaldson GC, Paul EA, et al. Effect of exacerbation on quality of life in patients with chronic obstructive pulmonary disease. Am J Respir Crit Care Med. 1998;157(5 Pt 1):1418-1422.

3. Hurst JR, Vestbo J, Anzueto A, et al. Evaluation of COPD Longitudinally to Identify Predictive Surrogate Endpoints (ECLIPSE) investigators. Susceptibility to exacerbation in chronic obstructive pulmonary disease. N Engl J Med. 2010;363(12):1128-1138.

4. Celli BR, Thomas NE, Anderson JA, et al. Effect of pharmacotherapy on rate of decline of lung function in chronic obstructive pulmonary disease: results from the TORCH study. Am J Respir Crit Care Med. 2008;178(4):332-338.

5. Zhang M, Li Q, Zhang XY, et al. Relevance of lower airway bacterial colonization, airway inflammation, and pulmonary function in the stable stage of chronic obstructive pulmonary disease. Eur J Clin Microbiol Infect Dis. 2010;29(12):1487-1493.

6. Sethi S, Murphy TF. Infection in the pathogenesis and course of chronic obstructive pulmonary disease. $N$ Engl J Med. 2008;359(22): 2355-2365.

7. Yusen RD. Evolution of the GOLD documents for the diagnosis, management, and prevention of chronic obstructive pulmonary disease. Controversies and questions. Am J Respir Crit Care Med. 2013;188(1): $4-5$.

8. Eller J, Ede A, Schaberg T, et al. Infective exacerbations of chronic bronchitis: relation between bacteriologic etiology and lung function. Chest. 1998;113(6):1542-1548. 
9. Miravitlles M, Espinosa C, Fernández-Laso E, et al. Relationship between bacterial flora in sputum and functional impairment in patients with acute exacerbations of COPD. Study Group of Bacterial Infection in COPD. Chest. 1999;116(1):40-46.

10. Soler N, Agustí C, Angrill J, et al. Bronchoscopic validation of the significance of sputum purulence in severe exacerbations of chronic obstructive pulmonary disease. Thorax. 2007;62(1):29-35.

11. Anthonisen NR, Manfreda J, Warren CP, et al. Antibiotic therapy in exacerbations of chronic obstructive pulmonary disease. Ann Intern Med. 1987;106(2):196-204.

12. Stockley RA, O'Brien C, Pye A, et al. Relationship of sputum color to nature and outpatient management of acute exacerbations of COPD. 2000. Chest. 2009;136(Suppl 5):e30.

13. Miravittles M. Epidemiology of chronic obstructive pulmonary disease exacerbations. Clin Pulm. Med. 2002;9(4):191-197.

14. Wedzicha JA, Donaldson GC. Exacerbations of chronic obstructive pulmonary disease. Respir Care. 2003;48(12):1204-1213.

15. Li XJ, Li Q, Si LY, et al. Bacteriological differences between COPD exacerbation and community-acquired pneumonia. Respir Care. 2011;56(11):1818-1824.

16. Roche N, Kouassi B, Rabbat A, et al. Yield of sputum microbiological examination in patients hospitalized for exacerbations of chronic obstructive pulmonary disease with purulent sputum. Respiration. 2007;74(1):19-25.

17. Huang YJ, Lynch SV, Wiener-Kronish JP. From microbe to microbiota: considering microbial community composition in infections and airway diseases. Am J Respir Crit Care Med. 2012;185(7):691-692.

18. Curran T, Coyle PV, McManus TE, et al. Evaluation of real-time PCR for the detection and quantification of bacteria in chronic obstructive pulmonary disease. FEMS Immunol Med Microbiol. 2007;50(1):112-118.

19. Morozumi M, Nakayama E, Iwata S, et al. Simultaneous detection of pathogens in clinical samples from patients with community-acquired pneumonia by real-time PCR with pathogen-specific molecular beacon probes. J Clin Microbiol. 2006;44(4):1440-1446.
20. Strålin K, Korsgaard J, Olcén P. Evaluation of a multiplex PCR for bacterial pathogens applied to bronchoalveolar lavage. Eur Respir J. 2006;28(3):568-575.

21. Brumfitt W, Willoughby Ml, Bromley LL. An evaluation of sputum examination in chronic bronchitis. Lancet. 1957;270(7009): 1306-1309.

22. Cabello H, Torres A, Celis R, et al. Bacterial colonization of distal airways in healthy subjects and chronic lung disease: a bronchoscopic study. Eur Respir J. 1997;10(5):1137-1144.

23. Rosell A, Monsó E, Soler N, et al. Microbiologic determinants of exacerbation in chronic obstructive pulmonary disease. Arch Intern Med. 2005;165(8):891-897.

24. Garcha DS, Thurston SJ, Patel AR, et al. Changes in prevalence and load of airway bacteria using quantitative PCR in stable and exacerbated COPD. Thorax. 2012;67(12):1075-1080.

25. Veeramachaneni SB, Sethi S. Pathogenesis of bacterial exacerbations of COPD. COPD. 2006;3(2):109-115.

26. Patel IS, Seemungal TA, Wilks M, et al. Relationship between bacterial colonisation and the frequency, character, and severity of COPD exacerbations. Thorax. 2002;57(9):759-764.

27. Sethi S, Evans N, Grant BJ, Murphy TF. New strains of bacteria and exacerbations of chronic obstructive pulmonary disease. NEngl J Med. 2002;347(7):465-471.

28. Perotin JM, Dury S, Renois F, et al. Detection of multiple viral and bacterial infections in acute exacerbation of chronic obstructive pulmonary disease: a pilot prospective study. J Med Virol. 2013;85(5) 866-873.
International Journal of COPD

\section{Publish your work in this journal}

The International Journal of COPD is an international, peer-reviewed journal of therapeutics and pharmacology focusing on concise rapid reporting of clinical studies and reviews in COPD. Special focus is given to the pathophysiological processes underlying the disease, intervention programs, patient focused education, and self management protocols.

\section{Dovepress}

This journal is indexed on PubMed Central, MedLine and CAS. The manuscript management system is completely online and includes a very quick and fair peer-review system, which is all easy to use. Visit http://www.dovepress.com/testimonials.php to read real quotes from published authors. 